\section{A Perspective on over 1000 Psychobooks for Psychiatry and Psychology Training}

Uma Perspectiva sobre 1000 Psicolivros no Ensino de Psiquiatria e Psicologia

Keywords: Books; Psychiatry/education; Psychology, Clinical/ education; Teaching

Palavras-chave: Ensino; Livros; Psicologia/educação; Psiquiatria/ educação

\section{To the Editor,}

We want to introduce readers to the new (old) concept of Psychobooks. The existence of Psychobooks was first hypothesized at some meetings of our group as being any kind of book that could interest and be of professional use to any mental health technician (e.g. psychiatrist, psychologist). That interest could be conscientious and explicit or implicit. The professional use could be for clinical or academic purposes, namely psychopharmacological or psychotherapeutic training.

We did a search with various terms: 'psychobooks', 'psychbooks', 'psycho books' and 'psycho-books' on PubMed. gov' $^{1}$ but we didn't obtain any results. But while googling ${ }^{2}$ 'psychobooks', we found many different uses for this term. We realized we did not invent the term as many internet websites referring to it already existed. The goodreads.com website included 1250 books under the category 'popular psycho books', ${ }^{3}$ with writings by prominent and respected physicians (e.g. Sigmund Freud or Oliver Sacks), but also classical or more contemporaneous authors (e.g. Fyodor Dostoyevsky or Sylvia Plath). Going through the whole list was exhausting but we felt that the Portuguese language was not represented. Many books in Portuguese were excluded, and even though some were essential and others were obscure, they also deserved inclusion in the list.

But how many types of psychobooks exist? We believe we can divide the list of psychobooks in different categories, depending on some of their characteristics:

- Books written, with a technical purpose, for teaching / training psychiatrists / psychologists.

- Books written, for the general public, by psychiatrists / psychologists.

- Books written, for the general public, by authors with a diagnosis of a psychiatric disorder.

- Books written, for the general public, where the protagonist(s) present(s) a psychiatric disorder.

What use can be found for psychobooks? We believe psychobooks can be important in terms of teaching, learning and knowledge development for mental health professionals, either in a technical field (e.g. psychopathology, psychopharmacology) or in a clinical setting (e.g. therapeutic alliance, psychotherapy). This educational use of arts for psychiatrists / psychologists is quite disseminated already for cinema and movies ${ }^{4}$ but should also be studied and de- veloped for books. On the other hand, psychobooks may also be valuable in the fight against stigma in mental health, particularly among the general public but also in medical students or even senior physicians in other medical specialties.

We implemented a voting system for all of our group collaborators. From February $1^{\text {st }} 2013$ to July $10^{\text {th }} 2018$ we invited all psychiatrists and psychologists, visiting our department at Psiquiatria Geral e Transcultural (PGT) or joining our meetings at Clube Regional de Folias (CRF), to participate in our unstructured survey. All we requested from participants was to name the psychobooks he/she ever read and to vote on each one, in a 40 point scale, from "-20 = terrible psychobook" to "+20 = excellent psychobook". After reaching one hundred voters we stopped data collection and made a basic statistical analysis.

During the five year timespan, we had a total of 250 meetings at the PGT department and CRF. During this five year period, we collected data from 100 participants, most of them psychiatrists and psychologists. All participants voted for their favorite psychobooks, so we ended up with a final list of 1149 titles. In Table 1, we present the top 10 list of our Psychobooks.

This is, to our knowledge, the first study regarding psychobooks. We feel that all of our 250 meetings not only contributed to the training of younger psychiatrist / psychologists but also enhanced the ever-evolving process of sharing knowledge and wisdom among senior professionals.

We have listed an impressive list of Portuguese and non-Portuguese psychobooks with a huge potential for teaching and sharing knowledge in psychiatry and psychology. Moreover, we believe that every participant in our ballot found at least one more interesting psychobook that sooner or later will become useful in his/her clinical practice and/or academic research.

Some of the biggest limitations of our work were: the convenience sample as all participants were invited; the absence of criteria for inclusion of the book in our list as any new book was accepted and could be included; and, finally, the asymmetry regarding the voting process, where two thirds of our psychobooks got only a single vote, some of them being quite obscure (even for us as authors).

Psychobooks exist: we asked about this concept to 100 psychiatrists / psychologists and we found more than 1000 . We're almost in the turn of the first quarter of the twenty first century but books are still among the most used sources of knowledge, especially for studying and training in psychiatry. ${ }^{5}$ Therefore, even though new ways of learning and training are emerging, we can't underestimate the educational potential of this quite old and traditional learning tool. Book sharing is an important way to share knowledge in the Medical field. Last but not the least, we believe there is huge potential regarding the adaptation of this method to many medical specialties (e.g. Neurobooks for Neurology). 


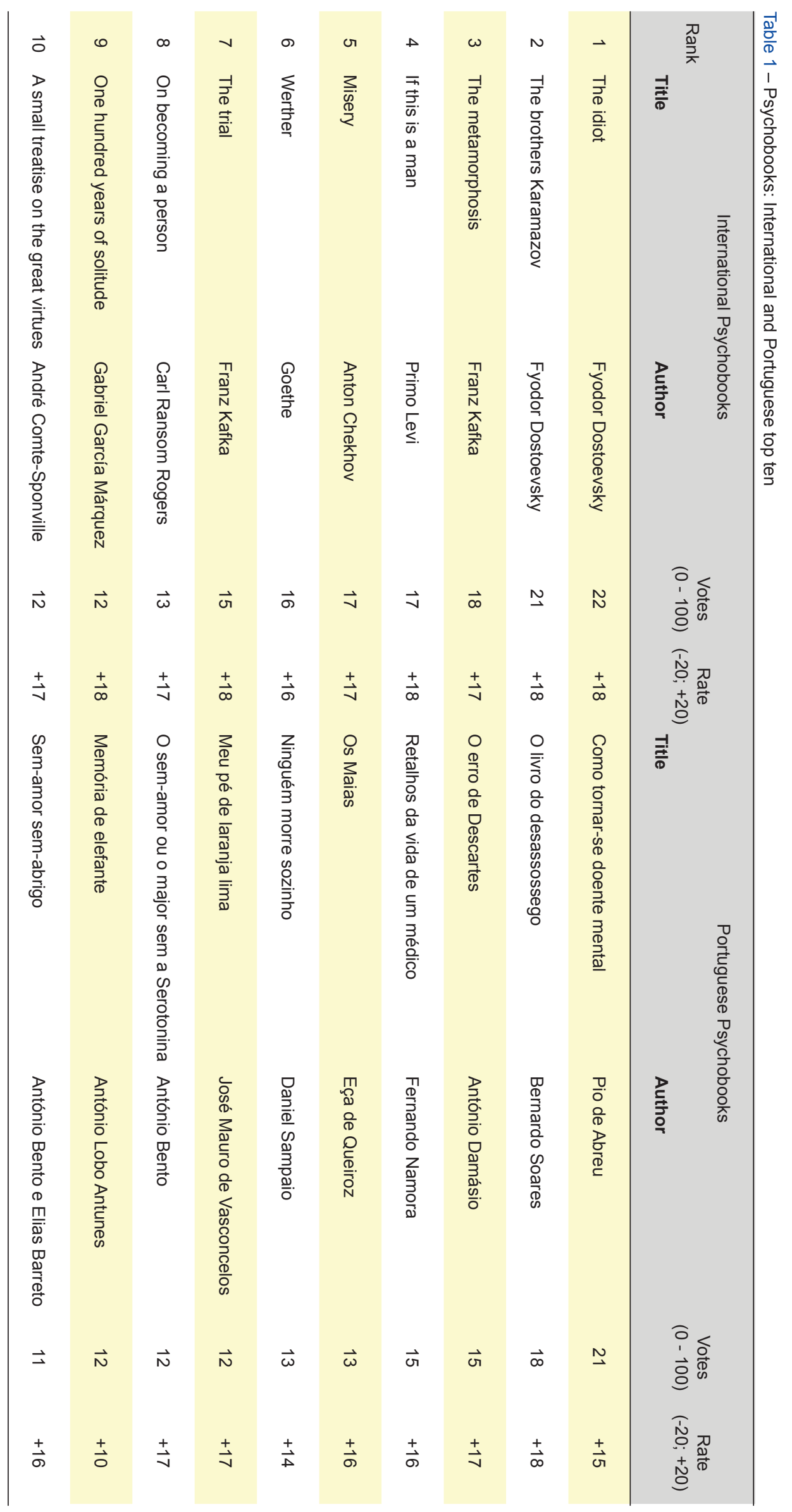




\section{CONFLICTS OF INTEREST}

On behalf of all authors, the corresponding author states that there is no conflict of interest.

\section{REFERENCES}

1. United States National Library of Medicine - National Institutes of Health [accessed 2018 Jul 11]. Available from: https://www.ncbi.nlm.nih.gov/ pubmed.

2. Google. [accessed 2019 May 8]. Available from: https://www.google.pt.

3. Goodreads. Popular Psycho Books. [accessed 2018 Jul 11]. Available from: https://www.goodreads.com/shelf/show/psycho.

\section{FUNDING SOURCES}

None

4. Marques JG, Adão F, Branco MJ. Madness at movies: psychopathology in 1968 Pasolini's theorem. Australas Psychiatry. 2015;23:190-1.

5. Gama Marques J, Pantovic Stefanovic M, Mitkovic-Voncina M, Riese F, Guloksuz S, Holmes K, et al. Equal access for all? Access to medical information for European psychiatric trainees. Psychiatry Res. 2016;238:150-2.

João GAMA MARQUES $\triangle^{1,2}$, Elias BARRETO ${ }^{1}$, Francisco MONIZ PEREIRA ${ }^{1,3}$, Isabel FERNANDES ${ }^{1}$, Rui DURVAL ${ }^{1,3}$, António BENTO1,4

1. Hospital Júlio de Matos. Centro Hospitalar Psiquiátrico de Lisboa. Lisboa. Portugal.

2. Clínica Universitária de Psiquiatria e Psicologia Médica. Faculdade de Medicina. Universidade de Lisboa. Lisboa. Portugal.

3. Departamento de Psicologia. Universidade Autónoma de Lisboa. Lisboa. Portugal.

4. Universidade Lusófona de Humanidades e Tecnologias. Lisboa. Portugal.

Autor correspondente: João Gama Marques. joaogamamarques@gmail.com

Recebido: 28 de outubro de 2019 - Aceite: 29 de outubro de 2019 | Copyright @ Ordem dos Médicos 2020

https://doi.org/10.20344/amp.13031

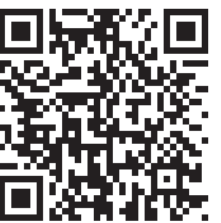

